\title{
Child health services during a COVID-19 outbreak in KwaZulu-Natal Province, South Africa
}

\author{
C Jensen, ${ }^{1}$ Cand Med (Norway), Dip HIV Man (SA); N H McKerrow, ${ }^{2}$ FC Paed (SA), MMed (Paed) \\ ${ }^{1}$ Health Systems Strengthening Unit, Health Systems Trust, Durban, South Africa \\ ${ }^{2}$ KwaZulu-Natal Department of Health; Department of Paediatrics and Child Health, Nelson Mandela School of Medicine, College of Health \\ Sciences, University of KwaZulu-Natal, Durban, South Africa; and Department of Paediatrics and Child Health, Faculty of Health Sciences, \\ University of Cape Town, South Africa
}

Corresponding author: C Jensen (cecijensen@gmail.com)

\begin{abstract}
Background. Current evidence indicates that children are relatively spared from direct COVID-19-related morbidity and mortality, but that the indirect effects of the pandemic pose significant risks to their health and wellbeing.

Objectives. To assess the impact of the local COVID-19 outbreak on routine child health services.

Methods. The District Health Information System data set for KwaZulu-Natal (KZN) provincial health services was accessed, and monthly child health-related data were extracted for the period January 2018 - June 2020. Chronological and geographical variations in sentinel indicators for service access, service delivery and the wellbeing of children were assessed.

Results. During April - June 2020, following the start of the COVID-19 outbreak in KZN, significant declines were seen for clinic attendance $(36 \% ; p=0.001)$ and hospital admissions $(50 \% ; p=0.005)$ of children aged $<5$ years, with a modest recovery in clinic attendance only. Among service delivery indicators, immunisation coverage recovered most rapidly, with vitamin A supplementation, deworming and food supplementation remaining low. Changes were less pronounced for in- and out-of-hospital births and uptake rates of infant polymerase chain reaction testing for HIV at birth, albeit with wide interdistrict variations, indicating inequalities in access to and provision of maternal and neonatal care. A temporary $47 \%$ increase in neonatal facility deaths was reported in May 2020 that could potentially be attributed to COVID-19-related disruption and diversion of health resources.

Conclusions. Multiple indicators demonstrated disruption in service access, service delivery and child wellbeing. Further studies are needed to establish the intermediate- and long-term impacts of the COVID-19 outbreak on child health, as well as strategies to mitigate these.
\end{abstract}

S Afr Med J 2021;111(2):114-119. https://doi.org/10.7196/SAMJ.2021.v111i2.15243

It is recognised that the SARS-CoV-2 outbreak has both direct and indirect effects on the health and wellbeing of children. ${ }^{[1-7]}$ The relative burden of SARS-CoV-2 infections among children and adolescents aged $<20$ years is low, ranging from $23 \%$ in Paraguay to $<1 \%$ in Spain, ${ }^{[1]}$ and children have largely been spared from severe infections, complications and deaths due to SARS-CoV-2. ${ }^{[1-5]}$ In South Africa (SA), children and adolescents aged $<18$ years have accounted for just $7.4 \%$ of confirmed cases ${ }^{[8]}$ and $3.2 \%$ of COVID-19associated hospital admissions, ${ }^{[9]}$ with a low incidence risk and case fatality rate in children aged $<5$ years. ${ }^{[8,9]}$

The indirect effects of COVID-19 arise from reduced coverage of child health interventions associated with the diversion of resources, and various societal responses to contain the spread of COVID-19 that lead to reduced economic activity and decreased household food security. Although these effects are difficult to quantify, they are of considerable concern for the paediatric population in both the short and medium term..$^{[1-3,6,7]}$ Experience from severe acute respiratory syndrome and Ebola outbreaks has demonstrated a reduction in coverage of health services, with maternal and child health being particularly vulnerable. ${ }^{[10,11]}$ SA experience has shown that a diversion of health resources during a measles campaign was associated with significant disruption in routine care, with declines in immunisation coverage, antenatal visits and contraceptive use. ${ }^{[12]}$ Roberton et al. ${ }^{[6]}$ applied the LiST (Lives Saved Tool) to model three scenarios, in which the coverage of essential health interventions was reduced by $10-52 \%$, to quantify the potential indirect of the COVID-19 pandemic on maternal and child mortality in low- and middleincome countries. The prevalence of malnutrition as evidenced by wasting increased by $10-50 \%$ per month and child mortality increased by $10-45 \%$, depending on the scenario.

A National State of Disaster was declared in SA on 15 March 2020 in response to the COVID-19 pandemic, with a national lockdown from 27 March. With stringent restriction of movement and a halt in economic activity, disruptions to routine health services and worsening health and wellbeing of children were anticipated. Declining household food security has been confirmed in subsequent telephonic household surveys that have indicated an $18 \%$ decline in employment rates from February to April 2020, while a fifth of respondents reported hunger during the previous 7 days. ${ }^{[13,14]}$ In households with children, one in seven reported child hunger during the preceding week, with $8 \%$ reporting this to be frequent (every day/almost every day). ${ }^{[14]}$ Although the World Health Organization has provided operational guidance for maintaining essential health services during epidemic outbreaks, ${ }^{[15]}$ international and local stakeholders may not have given adequate consideration and priority to the contingency of preventive and therapeutic services for children. ${ }^{[1,7,16-18]}$

\section{Objectives}

In view of the potential effects on health services and the documented social effects, this study was undertaken to assess the initial impact of the local COVID-19 outbreak on routine child health services. 


\section{Methods}

A retrospective review of the District Health Information System (DHIS) data set for the KwaZulu-Natal (KZN) provincial health services was conducted. The DHIS is an electronic platform for the routine reporting, analysis and dissemination of health data employed to monitor and manage programmes across all levels of the health service, including communities, clinics and hospitals. A National Indicator Data Set comprising data elements and indicators for 37 different domains is defined by the National Department of Health every 3 years. Examples of domains in the data set include child health and nutrition, maternal and newborn health, HIV, tuberculosis, clinic management, inpatient management, and more. Data are collected manually from facility registers at service delivery points, captured electronically at the facility, and then aggregated at the district, provincial and national levels. Routine monthly verification at facility level and quarterly analysis of aggregated or disaggregated data at provincial and district levels should be undertaken. The DHIS data set for KZN includes data from all health facilities in the province 589 fixed primary healthcare clinics (PHCs), 22 community health centres, 39 district hospitals, 13 regional hospitals, 1 tertiary hospital, 1 national central hospital and 16 specialised hospitals. These are spread across 11 districts, 7 predominantly rural, 1 predominantly urban, and 3 mixed urban and rural.

Data elements and indicators were reviewed to identify those that reflect maternal, newborn and child health. Eighteen data elements and 4 indicators representative of service access/utilisation, service delivery and the wellbeing of children were selected. Service access and utilisation represent the uptake of services by the general population across all levels of care in the health system. Elements relevant to children include clinic head counts, in- and out-ofhospital births, paediatric hospital admissions (separations), and bed utilisation rates. Delivery of child health services refers to the management of sick children as well as preventive (e.g. immunisations and vitamin A supplementation) and promotive (e.g. deworming, food supplementation, and polymerase chain reaction (PCR) testing for HIV at birth) programmes. Child wellbeing denotes the burden and management of and mortality from common childhood illnesses such as pneumonia, diarrhoea and malnutrition, and age-related mortality.

The data were extracted from the DHIS database on 12 - 19 June 2020 (January 2018 - June 2020 data) and 14 - 15 July 2020 (June 2020 data). Monthly data for each element and indicator were exported to an Excel 97-2003 workbook (Microsoft, USA) for further analysis. Outliers were identified, and numbers were verified and corrected with district information officers. Aggregated provincial and disaggregated district data were analysed for chronological trends and geographical (interdistrict) variations. Data element and indicator means were compared by calculating confidence intervals and $p$-values in Excel, and differences in means were considered statistically significant at a confidence level of $95 \%(p \leq 0.05)$. The chronological trends were ascertained by comparing the monthly mean for April - June 2020 with a baseline monthly mean constituting the 26 months preceding the COVID-19 outbreak (January 2018 February 2020). To account for seasonal variations in child wellbeing elements, the mean for April - June 2020 was compared with the mean for April - June 2019 rather than the baseline monthly mean.

Ethical approval for the study was granted by uMgungundlovu Health Ethics Review Board (ref. no. UHERB 005/2020).

\section{Results}

All data in the KZN Department of Health DHIS data set on the date of extraction were included in the analysis. Changes in data elements and indicators for each domain of child health (service access/utilisation, service provision and wellbeing of children) are summarised in Tables 1 - 3. The largest changes were observed during April and May 2020, at the start of the local COVID-19 outbreak and the level 5 national lockdown. Figs $1-3$ depict interdistrict variations in the percentage changes for selected data elements and indicators.

Table 1. Service access data elements and indicators

\begin{tabular}{lllllll}
\hline & Monthly mean, Jan 2018 - & \multicolumn{3}{c}{ Value (\% change from mean, Jan 2018 - Feb 2020) } \\
\cline { 2 - 5 } Data element/indicator & Feb 2020 (95\% CI) & Mar 2020 & Apr 2020 & May 2020 & Jun 2020 & p-value* \\
\hline Clinic head count $<5$ years, $n$ & $386951(376118-397784)$ & $403050(4)$ & $223792(-42)$ & $248434(-36)$ & $270041(-30)$ & 0.001 \\
Clinic head count 5 - 9 years, $n$ & $103469(98943-107995)$ & $109353(6)$ & $55701(-46)$ & $55838(-46)$ & $59053(-43)$ & 0.005 \\
Births in facility - total, $n$ & $17597(17070-18124)$ & $19569(11)$ & $16234(-8)$ & $16780(-5)$ & $17401(-1)$ & 0.10 \\
Born alive before arrival, $n$ & $882(852-912)$ & $871(-1)$ & $802(-9)$ & $953(8)$ & $902(2)$ & 0.50 \\
Paediatric separations, $n$ & $7156(6874-7439)$ & $7532(5)$ & $3669(-49)$ & $3292(-54)$ & $3820(-47)$ & 0.005 \\
Paediatric bed utilisation rate, \% & $50.4(48.4-52.4)$ & $50.0(-1)$ & $32.2(-36)$ & $30.8(-39)$ & $30.0(-40)$ & 0.005 \\
CI = confidence interval. & & & & & &
\end{tabular}

Table 2. Service delivery data elements and indicators

\begin{tabular}{|c|c|c|c|c|c|c|}
\hline \multirow[b]{2}{*}{ Data element/indicator } & \multirow{2}{*}{$\begin{array}{l}\text { Monthly mean, Jan } 2018 \text { - } \\
\text { Feb } 2020(95 \% \text { CI })\end{array}$} & \multicolumn{4}{|c|}{ Value (\% change from mean, Jan 2018 - Feb 2020) } & \multirow[b]{2}{*}{$p$-value ${ }^{*}$} \\
\hline & & Mar 2020 & Apr 2020 & May 2020 & Jun 2020 & \\
\hline Measles 1st dose coverage, $\%$ & $80.0(78.0-81.9)$ & $84.0(5)$ & $54.7(-32)$ & $72.5(-9)$ & $78.7(-2)$ & 0.005 \\
\hline Fully immunised $<1$ year coverage, $\%$ & $91.5(89.2-93.7)$ & $98.1(7)$ & $62.8(-31)$ & $83.9(-8)$ & $93.1(2)$ & 0.01 \\
\hline $\begin{array}{l}\text { Child }<5 \text { years on food } \\
\text { supplementation new, } n\end{array}$ & $1701(1597-1805)$ & $1694(0)$ & $783(-54)$ & $783(-54)$ & $798(-53)$ & 0.005 \\
\hline Vitamin A dose 12 - 59 months, $n$ & $123679(118613-128746)$ & $132716(7)$ & $44415(-64)$ & $63703(-48)$ & $71377(-42)$ & 0.001 \\
\hline $\begin{array}{l}\text { Infant } 1 \text { st } \mathrm{PCR}^{\dagger} \text { test at birth uptake } \\
\text { rate, } \%\end{array}$ & $93.9(92.4-95.4)$ & $89.6(-5)$ & $88.2(-6)$ & $80.1(-15)$ & $91.1(-3)$ & 0.01 \\
\hline
\end{tabular}


Table 3. Child wellbeing data elements

\begin{tabular}{|c|c|c|c|c|c|c|}
\hline \multirow[b]{2}{*}{ Data element/indicator } & \multirow{2}{*}{$\begin{array}{l}\text { Monthly mean, Jan } 2018 \text { - } \\
\text { Feb } 2020 \text { (95\% CI) }\end{array}$} & \multicolumn{4}{|c|}{ Value (\% change from mean, Jan 2018 - Feb 2020) } & \multirow[b]{2}{*}{$p$-value ${ }^{*}$} \\
\hline & & Mar 2020 & Apr 2020 & May 2020 & Jun 2020 & \\
\hline $\begin{array}{l}\text { Diarrhoea with dehydration new in child } \\
<5 \text { years, } n\end{array}$ & $863(791-935)$ & $680(-21)$ & $417(-52)$ & $296(-66)$ & $292(-66)$ & 0.01 \\
\hline Diarrhoea separation $<5$ years, $n$ & $719(632-806)$ & $879(22)$ & $324(-55)$ & $189(-74)$ & $177(-75)$ & 0.01 \\
\hline Diarrhoea death $<5$ years, $n$ & $14(12-16)$ & $16(16)$ & $20(44)$ & $6(-57)$ & $5(-64)$ & 0.50 \\
\hline Pneumonia new in child $<5$ years, $n$ & $3932(3506-4358)$ & $3683(-6)$ & $1213(-69)$ & $721(-82)$ & $928(-76)$ & 0.005 \\
\hline Pneumonia separation $<5$ years, $n$ & $922(802-1042)$ & $1024(11)$ & $384(-58)$ & $299(-75)$ & $340(-63)$ & 0.01 \\
\hline Pneumonia death $<5$ years, $n$ & $20(18-23)$ & $13(-36)$ & $6(-71)$ & $8(-61)$ & $9(-56)$ & 0.01 \\
\hline SAM in child $<5$ years new, $n$ & $203(184-222)$ & $235(16)$ & $117(-42)$ & $142(-30)$ & $103(-49)$ & 0.50 \\
\hline SAM inpatient $<5$ years, $n$ & $190(171-209)$ & $241(27)$ & $126(-34)$ & $124(-35)$ & $92(-52)$ & 0.50 \\
\hline SAM death $<5$ years, $n$ & $15(13-17)$ & $17(11)$ & $15(0)$ & $14(-8)$ & $12(-21)$ & 0.50 \\
\hline Death in facility 0 - 28 days, $n$ & $193(185-201)$ & $239(24)$ & $204(6)$ & $283(47)$ & $193(0)$ & 0.025 \\
\hline Death in facility 28 days - 59 months, $n$ & $92(87-96)$ & $92(0)$ & $55(-40)$ & $68(-26)$ & $62(-32)$ & 0.005 \\
\hline
\end{tabular}

\section{Service access and utilisation}

Provincially, both clinic attendance $(p=0.001)$ and hospital admissions $(p=0.005)$ of children aged $<5$ years dropped significantly during April to June 2020 compared with the baseline monthly average (Table 1). The largest reduction $(42 \%)$ in clinic $<5$ head counts occurred in April (Fig. 4), with a modest recovery in May (36\%) and June $(30 \%)$. The initial decline in clinic attendance for age groups $>10$ years was less pronounced, $26-33 \%$ for patients aged $10-19$ years and $17-20 \%$ for patients aged $>20$ years, albeit with less recovery in May and June. Community-based services for children also declined in April, by $85 \%$ at community (Phila Mntwana) centres and by $54 \%$ at the household level, with the household services recovering sooner than the facility attendance. Paediatric separations (discharges, transfers out and deaths) were used as proxy indicators for hospital admissions and showed a significant decline with little recovery - 49\%, 54\% and $47 \%$ reductions in April, May and June, respectively. Paediatric hospital bed utilisation rates (bed occupancy) followed a similar pattern. Maternity and newborn data were less consistent, with a decrease in in-hospital births (8\%; $p=0.1)$ in April and some recovery thereafter, while births before arrival (BBA) also declined initially with a substantial increase thereafter. The increase in BBA was influenced by large increases in two districts, Uthukela and Harry Gwala, which were not associated with an equivalent decrease in in-facility births. Primary care services showed some recovery while hospital services displayed little, and no clear relationship was seen between inand out-of-hospital births. Under-5 PHC head counts and paediatric separations

\begin{tabular}{|c|c|c|c|c|c|c|}
\hline District & $\begin{array}{l}\% \text { of KZN } \\
\text { population } \\
<5 \text { years }\end{array}$ & Setting & $\begin{array}{c}\text { PHC } \\
\text { head count } \\
<5 \text { years, } \%\end{array}$ & $\begin{array}{l}\text { Facility } \\
\text { births, \% }\end{array}$ & $\begin{array}{l}\text { Born before } \\
\text { arrival, } \%\end{array}$ & $\begin{array}{c}\text { Paediatric } \\
\text { separations, } \%\end{array}$ \\
\hline eThekwini & 30 & Urban & -49 & -9 & 1 & -59 \\
\hline iLembe & 6 & Rural & -43 & -17 & -32 & -58 \\
\hline Ugu & 8 & Mixed & -39 & -2 & -16 & -50 \\
\hline Amajuba & 6 & Rural & -26 & -3 & -34 & -49 \\
\hline Harry Gwala & 6 & Rural & -38 & 3 & 32 & -57 \\
\hline uMgungundlovu & 10 & Mixed & -37 & -4 & 1 & -50 \\
\hline Umzinyathi & 6 & Rural & -28 & -7 & -21 & -50 \\
\hline Uthukela & 8 & Rural & -31 & -1 & 76 & -51 \\
\hline King Cetshwayo & 11 & Mixed & -39 & -13 & 3 & -36 \\
\hline Umkhanyakude & 8 & Rural & -35 & 1 & -33 & -46 \\
\hline Zululand & 10 & Rural & -29 & 1 & -19 & -40 \\
\hline
\end{tabular}

Fig. 1. Changes in service access by district (mean for April - May 2020 compared with mean for January 2018 - February 2020). (KZN = KwaZulu-Natal; PHC = primary healthcare facility.)

\begin{tabular}{|c|c|c|c|c|c|c|}
\hline District & $\begin{array}{l}\% \text { of KZN } \\
\text { population } \\
<5 \text { years }\end{array}$ & Setting & $\begin{array}{l}\text { Measles } \\
\text { 1st-dose } \\
\text { coverage, \% }\end{array}$ & $\begin{array}{c}\text { Child }<5 \text { years } \\
\text { on food } \\
\text { supplementation, } \%\end{array}$ & $\begin{array}{l}\text { Vitamin A } \\
\text { dose } 12-50 \\
\text { months, } \%\end{array}$ & $\begin{array}{c}\text { Infant PCR at } \\
\text { birth uptake, \% }\end{array}$ \\
\hline eThekwini & 30 & Urban & -37 & -59 & -54 & -17 \\
\hline iLembe & 6 & Rural & -26 & -59 & -66 & -9 \\
\hline Ugu & 8 & Mixed & -10 & -85 & -49 & 3 \\
\hline Amajuba & 6 & Rural & -14 & -30 & -64 & -21 \\
\hline Harry Gwala & 6 & Rural & -9 & -66 & -52 & -4 \\
\hline uMgungundlovu & 10 & Mixed & -15 & -39 & -55 & -17 \\
\hline Umzinyathi & 6 & Rural & -12 & -42 & -45 & 9 \\
\hline Uthukela & 8 & Rural & -5 & -49 & -63 & 12 \\
\hline King Cetshwayo & 11 & Mixed & -17 & -54 & -58 & 4 \\
\hline Umkhanyakude & 8 & Rural & -16 & -60 & -56 & -8 \\
\hline Zululand & 10 & Rural & -10 & -53 & -59 & -26 \\
\hline
\end{tabular}

Fig. 2. Changes in service delivery by district (mean for April - May 2020 compared with mean for January 2018 - February 2020). (KZN = KwaZulu-Natal; PCR = polymerase chain reaction testing for HIV at birth.)

\begin{tabular}{|c|c|c|c|c|c|c|}
\hline District & $\begin{array}{c}\% \text { of KZN } \\
\text { population } \\
<5 \text { years }\end{array}$ & Setting & $\begin{array}{l}\text { Pneumonia new } \\
\text { in child }<5 \text { years }\end{array}$ & $\begin{array}{l}\text { Diarrhoea with } \\
\text { dehydration new } \\
\text { in child }<5 \text { years }\end{array}$ & $\begin{array}{l}\text { SAM new } \\
\text { in child } \\
<5 \text { years }\end{array}$ & $\begin{array}{l}\text { Death in } \\
\text { facility } \\
0-28 \text { days }\end{array}$ \\
\hline eThekwini & 30 & Urban & -77 & -75 & -38 & 24 \\
\hline iLembe & 6 & Rural & -66 & -21 & -22 & 8 \\
\hline Ugu & 8 & Mixed & -82 & -61 & -29 & 23 \\
\hline Amajuba & 6 & Rural & -72 & -36 & -63 & 50 \\
\hline Harry Gwala & 6 & Rural & -72 & -30 & -73 & 57 \\
\hline uMgungundlovu & 10 & Mixed & -61 & -46 & -61 & 32 \\
\hline Umzinyathi & 6 & Rural & -78 & -59 & -36 & -19 \\
\hline Uthukela & 8 & Rural & -80 & -57 & -58 & 41 \\
\hline King Cetshwayo & 11 & Mixed & -76 & -57 & -25 & - \\
\hline Umkhanyakude & 8 & Rural & -87 & -25 & -61 & -12 \\
\hline Zululand & 10 & Rural & -78 & -43 & 10 & 65 \\
\hline
\end{tabular}

Fig. 3. Changes in child wellbeing by district (mean for April - May 2020 compared with mean for January 2018 - February 2020). (KZN = KwaZulu-Natal; SAM = severe acute malnutrition.) 
declined across all districts, with a twofold variation between districts. The greatest declines occurred in eThekwini and iLembe districts, which had the highest COVID-19 incidence risk at the time (Fig. 1). There was no uniform change in maternity data, with both increased and decreased figures and a wide variability between districts.

\section{Service delivery}

The various immunisation indicators demonstrated similar trends to 'measles first-dose coverage' and 'fully immunised $<1$ year', with $\sim 30 \%$ reduction in April 2020 followed by a smaller, 5 - 10\%, reduction in May, and nearnormal values by June (Fig. 5, Table 2). The reductions in immunisation coverage were less pronounced and of shorter duration than the decline in clinic attendance for children aged $<5$ years. A significant decline $(p=0.001)$ was seen in vitamin A supplementation, with minimal recovery over the 3 months, and deworming treatment followed a similar trend. Nutrition supplementation dropped to around half from April 2020, with no recovery by June. The 'infant PCR at birth uptake rate' was used to reflect hospital-based services and demonstrated smaller but significant $(p=0.01)$ reductions. Interdistrict variability in 'measles first-dose coverage' was wide (nine-fold), largely owing to the reductions in eThekwini and iLembe (Fig. 2). There was a 3 -fold variation across the remaining districts, which is more in keeping with the reduction seen in $<5 \mathrm{PHC}$ attendance. Food and vitamin A supplementation demonstrated greater declines with less variability between districts. Large variations were seen for the 'infant PCR at birth uptake rate, again indicating possible inequalities in hospital-level maternity and neonatal service delivery.

\section{Child wellbeing}

A $47 \%$ increase in in-facility newborn (0 28 days) deaths was reported in May 2020, i.e. 283 deaths provincially compared with a monthly mean of 193 deaths (Fig. 6, Table 3). From April to June 2020, 66 additional neonatal facility deaths were reported compared with April - June 2019 ( $p=0.025$ ), and 116 additional deaths compared with the same period in 2018. Facility deaths for children aged 29 days - 59 months declined, although the mortality reduction was not as large as the decline in hospital admissions. Compared with April - June 2019, significantly fewer children presented to healthcare facilities during April - June 2020 with diarrhoea $(p=0.01)$ and lower respiratory tract infections $(p=0.005)$, with corresponding declines in facility admissions and deaths due to these conditions. Nonsignificant reductions $(p=0.50)$ were seen for numbers of new cases, admissions and deaths from severe acute malnutrition (SAM). A temporal trend of return towards normal was seen for deaths in facilities and to a lesser degree for new cases of pneumonia. Diarrhoea cases remained low, while no clear chronological pattern was seen for the number of SAM cases (Table 3). When the child wellbeing elements are disaggregated at the district level, the absolute numbers are low and a small change in absolute numbers is reflected as a large percentage change. The changes must therefore be interpreted with caution, particularly for deaths in facility at 0 - 28 days (Fig. 3). Of the child wellbeing elements, deaths in facilities at $0-28$ days increased in most districts and displayed the greatest interdistrict variability.

\section{Discussion}

The above data confirm the anticipated impact of the COVID-19 pandemic on child health services, with a pattern of disruption across multiple data elements and indicators covering service access, service delivery and child wellbeing. Hospital admissions displayed greater reductions and less recovery than $\mathrm{PHC}$ clinic attendance, and service access was reduced to a greater extent for young children than for adults and adolescents. A pattern of disproportionate decline in service access for children is consistent with the assessment of clinic attendance in rural KZN reported by Siedner

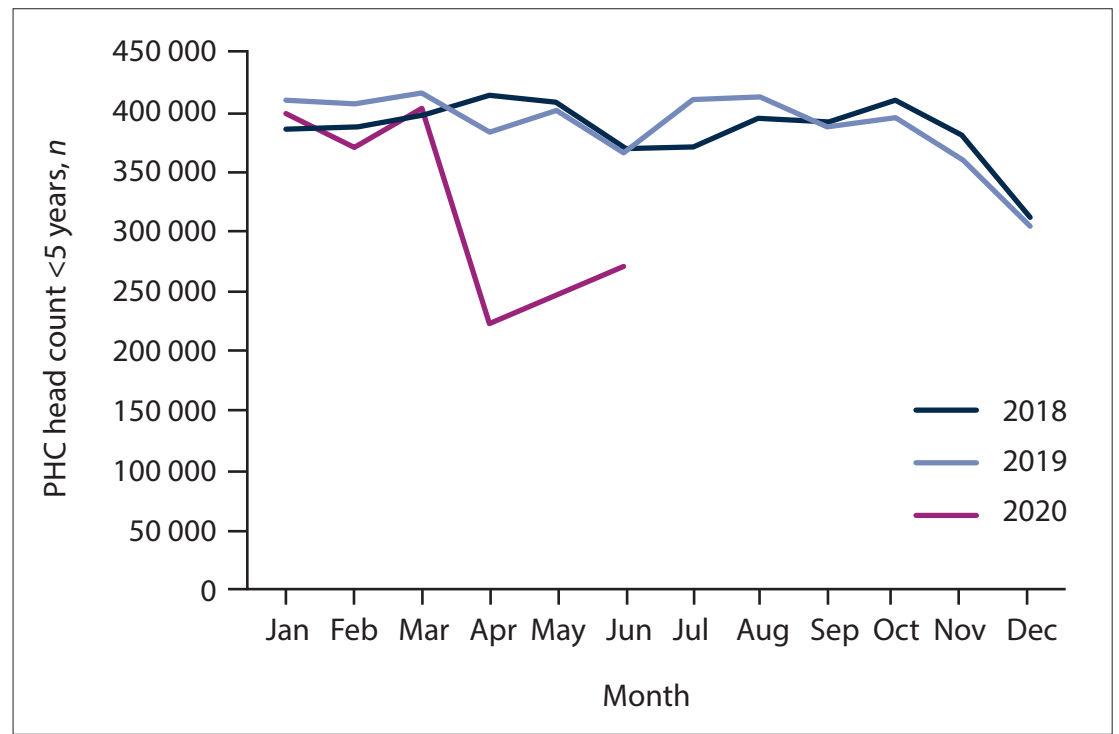

Fig. 4. Primary healthcare facility head count $<5$ years in KwaZulu-Natal by year and month.

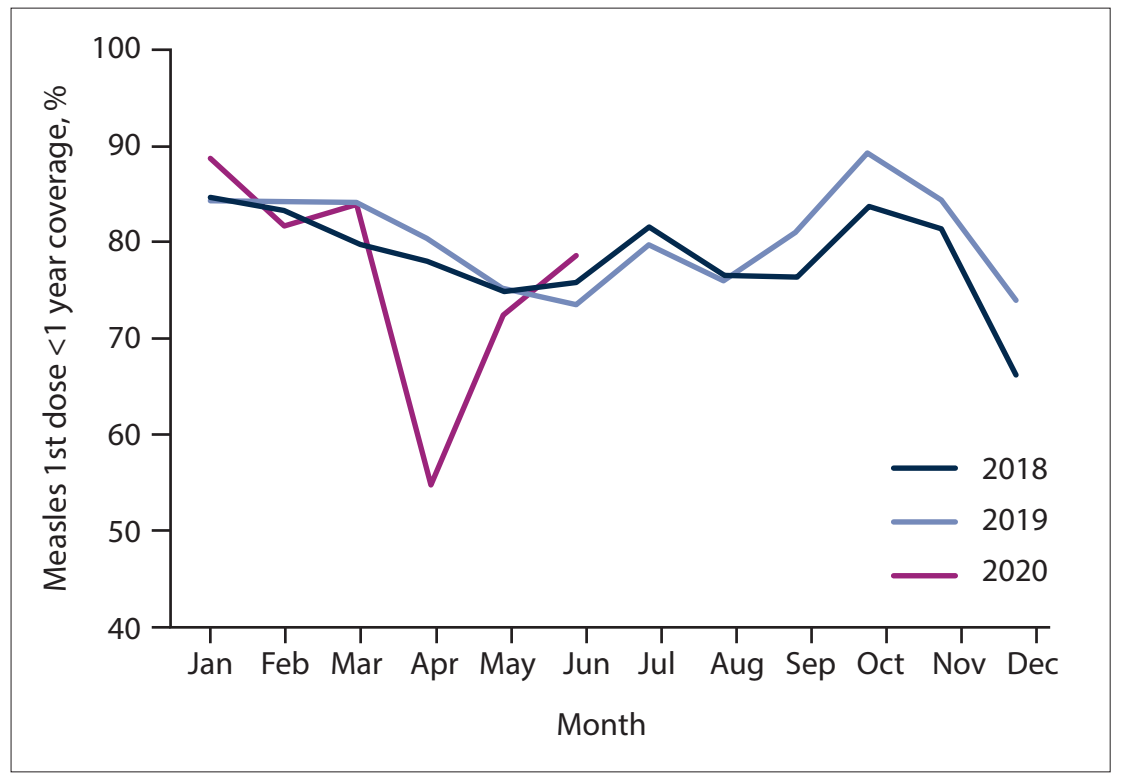

Fig. 5. Measles first dose $<1$ year coverage in KwaZulu-Natal by year and month. 


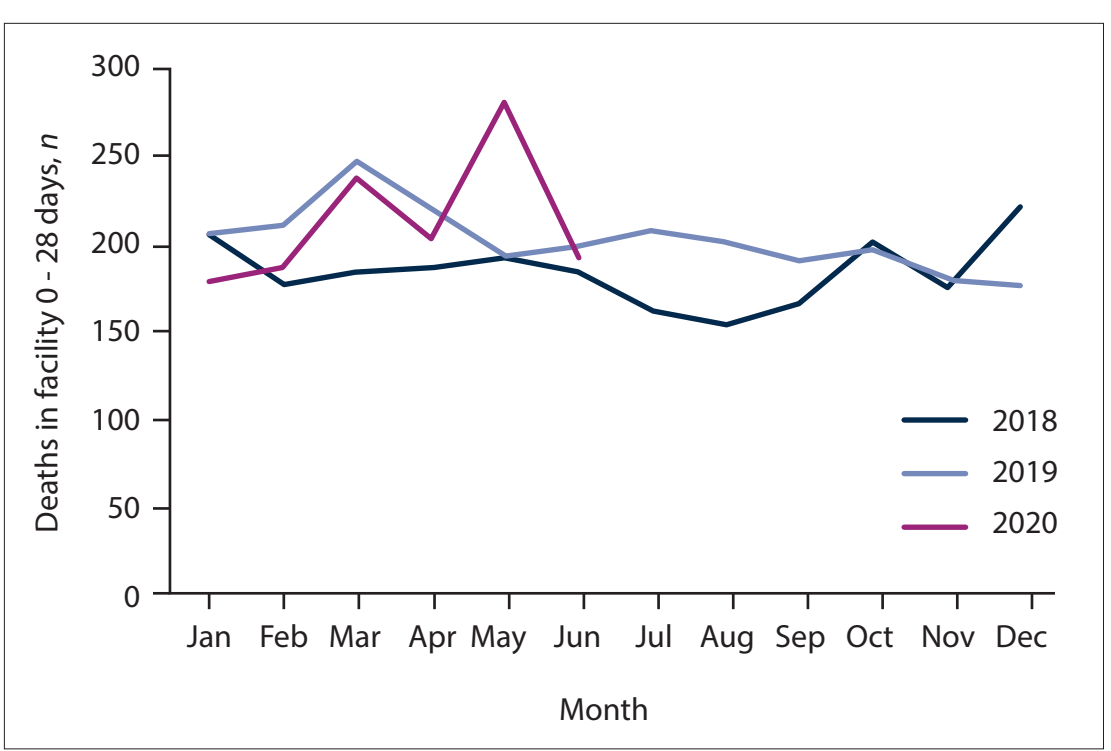

Fig. 6. Deaths in facility at $0-28$ days in KwaZulu-Natal by year and month.

et al. ${ }^{[19]}$ Population surveys have suggested that the fear of contracting COVID-19 infection has influenced health-seeking behaviour more than the availability of health services or transport challenges. ${ }^{[13,20]}$ Clinic attendance for adults demonstrated little recovery, which may reflect a high prevalence of chronic diseases ${ }^{[21]}$ conducive to alternative service delivery strategies such as multi-month prescriptions and central chronic medicines dispensing and distribution. Clinic visits for children are often to access acute care or preventive programmes (e.g. immunisation and weight monitoring), which are less readily provided outside health facilities. During the recovery period, uptake of facilitybased services seemed to be lagging behind the recovery seen in communitybased services. This finding may reflect a temporary community-level task-shift towards COVID-19 screening, as well as continued avoidance of facility visits due to fears of contracting COVID-19. Among service delivery indicators, immunisation coverage recovered most quickly, while vitamin A supplementation, deworming and food supplementation remained low. In March 2020, the initial response from health authorities was to temporarily suspend routine immunisation services to limit the spread of COVID-19, ${ }^{[22,23]}$ and public messages strongly emphasised the need to stay at home. Subsequent advocacy from local stakeholders ${ }^{[16,23,24]}$ may have contributed to an increased urgency around the resumption of immunisation services.

Deterioration in child nutrition is currently a key concern locally and internationally. Unfortunately, routine DHIS data collection has not included good early indicators for childhood malnutrition. New cases, admissions, and deaths from moderate acute malnutrition were recently included in the DHIS data set. However, changes in these elements could not be described without baseline data for comparison. A reduced number of children presented to clinics and hospitals with SAM in April - June 2020, although the number of SAM deaths in facilities did not change significantly. Consequently, the case fatality rate for SAM increased, but based on a reduced denominator. Furthermore, DHIS data only report malnutrition cases presenting to facilities, so that concerns remain around increased community occurrence of childhood malnutrition and stunting. Household surveys conducted during the national lockdown period have indicated an extensive impact on food security and hunger, ${ }^{[14]}$ and an increased number of children presenting to facilities with malnutrition is anticipated going forward. The numbers of children presenting to facilities with respiratory conditions and diarrhoea dropped more than the reductions in clinic attendance and hospital admissions could account for. Furthermore, the expected seasonal rise in respiratory diseases such as respiratory syncytial virus was not evident. Movement restrictions, behavioural infection control interventions, and closure of schools and crèches may have decreased children's exposure to pathogens, with a resulting decline in the incidence of common childhood infections. Although temporary, the provincial increase in newborn (0 - 28 days) facility deaths is a reason for concern, particularly when considering the concomitant reduction in facility births. A surge in newborn facility deaths would highlight the vulnerability of the youngest patients and may allude to COVID-19-related resource diversion and health systems disruptions. Neonatal care capacity may have been reduced temporarily in the province as a result of restructuring of health facilities, quarantining of health workers, and 2-week closure of a regional hospital in early May 2020.

The first SA case of COVID-19 was documented in uMgungundlovu district on 5 March 2020, but the urban district eThekwini quickly became the provincial epicentre and iLembe district experienced cluster outbreaks from April. SARS-CoV-2 transmission was reasonably well controlled in most other districts until mid-June, when the number of cases increased rapidly, particularly in uMgungundlovu district. ${ }^{[25]}$ eThekwini and iLembe districts did indeed experience the largest reductions in under5 clinic attendance and hospital admission, indicating that the local COVID-19 outbreak may have adversely affected access to clinicand hospital-level healthcare.

\section{Study limitations and strengths}

Important limitations of the study include potential inaccuracies in the DHIS data set. The routine DHIS data collection and capturing process involves multiple manual and electronic steps, leaving room for human error. Several levels of data verification are meant to mitigate the risk of inaccuracy, ${ }^{[26]}$ but such routines may have been conducted less regularly during the COVID-19 outbreak. Additionally, the DHIS data only provide information about children presenting to healthcare facilities. As some children in need of healthcare may have remained at home during this period, the impact of the COVID-19 outbreak on child health is probably larger and certainly more complex than reflected by the data presented here. Nevertheless, this study provides a quantitative assessment of the impact of COVID-19 on child health, employing a relatively large data set including all public health facilities in the province. To our knowledge, few previous reports address the impact of COVID-19 and associated outbreak responses on child health indicators, and similar disruptions are likely to occur in other SA provinces as well as in other low- to middle-income settings.

\section{Recommendations}

Although children are less severely affected by SARS-CoV-2 infection than adults, they 
represent a vulnerable population that is profoundly affected by the pandemic's indirect effects on social determinants of health and the allocation of health resources. There is a need to ring-fence resources and actively promote essential services for children to avoid a pernicious deterioration in child health and survival. To reach the children most at risk, stakeholders involved in education, child protection, nutrition and health services could collaborate to target impoverished areas with support programmes. Further studies are required to establish the long-term impacts of the COVID-19 outbreak on child health as well as strategies to mitigate these. Early indicators for child nutrition are needed, including process indicators. Community-level data on child wellbeing would help form a more complete picture of the current status of child health. Ongoing surveillance and response to changes in service delivery and child wellbeing are crucial to avoid loss of hard-won gains in child health and survival.

\section{Conclusions}

During April - June 2020, following the start of the KZN COVID-19 outbreak, a pattern of disruption was seen with significant changes across multiple indicators for service access, service delivery and the wellbeing of children. A temporary $47 \%$ increase in neonatal facility deaths was reported in May 2020 that could potentially be attributed to COVID-19-related disruption and diversion of health resources. Further studies are needed to establish the intermediate- and longterm impacts of the COVID-19 outbreak on child health as well as strategies to mitigate these.

\section{Declaration. None.}

Acknowledgements. None.

Author contributions. NHM and CJ conceptualised the article. NHM extracted the DHIS data and CJ generated the tables and charts. CJ and NHM wrote the article.

Funding. The work was supported by the ELMA Foundation under the 'Unfinished Business' grant. The funding organisation had no role in the design, implementation, interpretation or publication of the study. Conflicts of interest. None.

\footnotetext{
1. Mofenson LM, Idele P, Anthony D, et al., for UNICEF Office of Research. The evolving epidemiologic and clinical picture of SARS-CoV-2 and COVID-19 disease in children and young people. United Nations Children's Fund (UNICEF) Office of Research, August 2020. https://www.unicef-irc.org/ publications/1107-the-evolving-epidemiologic-and-clinical-picture-of-sars-cov-2-and-covid-19disease.html (accessed 29 October 2020).

2. United Nations. Policy Brief: Impact of COVID-19 on children. April 2020. https://unsdg.un.org/ resources/policy-brief-impact-covid-19-children (accessed 29 October 2020).

3. Cornia GA, Jolly R, Stewart F. COVID-19 and children, in the North and in the South. United Nations Children's Fund (UNICEF), 2020. https://reliefweb.int/report/world/covid-19-and-children-north-
} and-south (accessed 29 October 2020).
4. Hoang A, Chorath K, Moeraira A, et al. COVID-19 in 7780 paediatric patients: A systematic review. Lancet E Clin Med 2020;24:100433. https://doi.org/10.1016/j.eclinm.2020.100433

5. Castagnoli R, Votto M, Licari A, et al. Severe acute respiratory syndrome coronavirus 2 (SARS5. Castagnoli R, Votto M, Licari A, et al. Severe acute respiratory syndrome coronavirus 2 (SARS-
$\mathrm{CoV}-2$ ) infection in children and adolescents: A systematic review. JAMA Pediatr 2020;174(9):882889. https//doi.org/10.1001/jamapediatrics.2020.1467

6. Roberton T, Carter ED, Chou VB, et al. Early estimates of the indirect effects of the COVID-19 pandemic on maternal and child mortality in low-income and middle-income countries: A modelling study. Lancet Glob Health 2020;8(7):E901-E908. https://doi.org/10.1016/S2214109X(20)30229-1

7. Independent Expert Group of the Global Nutrition Report. 2020 Global Nutrition Report: Action on equity to end malnutrition. Bristol: Development Initiatives, 2020. https://globalnutritionreport. org/reports/2020-global-nutrition-report/executive-summary/ (accessed 29 October 2020).

8. National Institute for Communicable Diseases. COVID-19 weekly epidemiological brief: South Africa, week 31, 2020. https://www.nicd.ac.za/wp-content/uploads/2020/08/NICD-WeeklyEpidemiological-Brief_-Week-ending-01-August-2020.pdf (accessed 29 October 2020).

9. National Institute for Communicable Diseases. COVID-19 IMT, COVID-19 response team and DATCOV teams. Epidemiology and clinical characteristics of laboratory-confirmed cases of DATCOV teams. Epidemiology and clinical characteristics of laboratory-confirmed cases of
COVID-19 aged $\leq 18$ years: South Africa, 3 March 2020 - 25 July 2020. https://www.nicd.ac.za/ COVID-19 aged $\leq 18$ years: South Africa, 3 March $2020-25$ July 2020. https://www.nicd.ac.za/
wp-content/uploads/2020/08/Epidemiology-Covid-Under-18-years-V2.pdf (accessed 29 October 2020).

10. Sochas L, Channon AA, Nam S. Counting indirect crisis-related deaths in the context of a lowresilience health system: The case of maternal and neonatal health during the Ebola epidemic in Sierra Leone. Health Policy Plan 2017;32(Suppl 3):32-39. https://doi.org/10.1093/heapol/czx108

11. Chang HJ, Huang N, Lee CH, et al. The impact of the SARS epidemic on the utilization of medical services: SARS and the fear of SARS. Am J Public Health 2004;94(4):562-564. https://doi. org/10.2105/ajph.94.4.562

12. Verguet S, Jassat W, Bertram MY, et al. Impact of supplemental immunisation activity (SIA) campaigns on health systems: Findings from South Africa. J Epidemiol Community Health 2013;67(11):947-952. https://doi.org/10.1136/jech-2012-202216

13. Spaull N, Ardington C, Bassier H, et al. Overview and findings: NIDS-CRAM Synthesis Report Wave 1. NIDS-CRAM Technical Document, 30 September 2020. https://cramsurvey.org/reports/ (accessed 29 October 2020).

14. Wills G, Patel L, van der Berg S, Mpeta B. Household resource flows and food poverty during South Wills G, Patel L, van der Berg S, Mpeta B. Household resource flows and food poverty during South
Africass lockdown: Short-term policy implications for three channels of social protection. NIDSAfrica's lockdown: Short-term policy implications for three channels of social protection. NIDS-
CRAM Technical Document, 15 July 2020. https://cramsurvey.org/reports/ (accessed 29 October CRAM).

15. World Health Organization. COVID-19: Operational guidance for maintaining essential health services during an outbreak. 1 June 2020. https://www.who.int/publications-detail/covid-19operational-guidance-for-maintaining-essential-health-services-during-an-outbreak (accessed 29 October 2020)

16. Hofman K, Madhi S. The unanticipated costs of COVID-19 to South Africa's quadruple disease burden. S Afr Med J 2020;110(8):698-699. https://doi.org/10.7196/SAMJ.2020.v110i8.15125

17. Fore H. A wake-up call: COVID-19 and its impact on children's health and wellbeing. Lancet Glob Health 2020;8(7):E861-E862. https://doi.org/10.1016/S2214-109X(20)30238-2

18. Menendez C, Gonzalez R, Donnay F, Leke RGF. Avoiding indirect effects of COVID-19 on maternal and child health. Lancet Glob Health 2020;8(7):E863-E864. https://doi.org/10.1016/S2214$109 \mathrm{X}(20) 30239-4$

19. Siedner MJ, Kraemer JD, Meyer MJ, et al. Access to primary healthcare during lockdown measures for COVID-19 in rural South Africa: A longitudinal study. medRxiv 2020 (epub 20 May 2020), https://doi.org/10.1101/2020.05.15.20103226

20. Khosa C, du Plessis R. Behavioural and health impacts of the COVID-19 pandemic in South Africa. Pretoria: Statistics South Africa, 2020. http://www.statssa.gov.za/publications/Report-00-80-02/ Report-00-80-022020.pdf (accessed 29 October 2020).

21. Massyn N, Barron P, Day C, et al. District Health Barometer 2018/19. Durban: Health Systems Trust, 2020. https://www.hst.org.za/publications/Pages/DISTRICT-HEALTH-BAROMETER-201819.aspx (accessed 29 October 2020)

22. West Rand Health District. Public Notice: Decanting of primary health facilities. Johannesburg: Gauteng Department of Health, 2020.

23. National Advisory Group on Immunisation. Guidance on routine immunisation services during the COVID-19 pandemic. Pretoria: National Department of Health, 2020.

24. National Department of Health, South Africa. COVID-19 guidance for facility managers and professional health workers in primary health care facilities. Pretoria: $\mathrm{NDoH}, 2020$.

5. Baphela MP, Mhlongo B. KwaZulu-Natal Department of Health COVID-19 situational report: 21 July 2020. Pietermaritzburg: KwaZulu-Natal Department of Health, 2020.

21 July 2020. Pietermaritzburg: KwaZulu-Natal Department of Health, 2020. National Department of Health, South Africa. District Health Management Information System
(DHMIS) Standard Operating Procedures: Facility level. Pretoria: NDoH, 2016. https://www. knowledgehub.org.za/system/files/elibdownloads/2019-10/FACILITY\%20LEVEL\%20SOP.pdf
knt (accessed 29 October 2020)

Accepted 17 November 2020. 